\title{
Age-Related Differences in Neural Activity during Memory Encoding and Retrieval: A Positron Emission Tomography Study
}

\author{
Roberto Cabeza, ${ }^{1}$ Cheryl L. Grady, ${ }^{1}$ Lars Nyberg, ${ }^{2}$ Anthony R. McIntosh, ${ }^{1}$ Endel Tulving, ${ }^{1}$ Shitij Kapur, ${ }^{1,3}$ \\ Janine M. Jennings, ${ }^{1}$ Sylvain Houle, ${ }^{3}$ and Fergus I. M. Craik ${ }^{1}$ \\ ${ }^{1}$ Rotman Research Institute of Baycrest Centre, University of Toronto, Toronto, Ontario, Canada M6A 2E1, ${ }^{2}$ Department \\ of Psychology, University of Umeå, S-90187 Umeå, Sweden, and ${ }^{3} P E T$ Centre, Clarke Institute of Psychiatry, University \\ of Toronto, Toronto, Ontario, Canada M6A 2E1
}

Positron emission tomography (PET) was used to compare regional cerebral blood flow (rCBF) in young (mean 26 years) and old (mean 70 years) subjects while they were encoding, recognizing, and recalling word pairs. A multivariate partialleast-squares (PLS) analysis of the data was used to identify age-related neural changes associated with (1) encoding versus retrieval and (2) recognition versus recall. Young subjects showed higher activation than old subjects (1) in left prefrontal and occipito-temporal regions during encoding and (2) in right prefrontal and parietal regions during retrieval. Old subjects showed relatively higher activation than young subjects in several regions, including insular regions during encoding, cuneus/ precuneus regions during recognition, and left prefrontal regions during recall. Frontal activity in young subjects was leftlateralized during encoding and right-lateralized during recall [hemispheric encoding/retrieval asymmetry (HERA)], whereas old adults showed little frontal activity during encoding and a more bilateral pattern of frontal activation during retrieval. In young subjects, activation in recall was higher than that in recognition in cerebellar and cingulate regions, whereas recognition showed higher activity in right temporal and parietal regions. In old subjects, the differences in blood flow between recall and recognition were smaller in these regions, yet more pronounced in other regions. Taken together, the results indicate that advanced age is associated with neural changes in the brain systems underlying encoding, recognition, and recall. These changes take two forms: (1) age-related decreases in local regional activity, which may signal less efficient processing by the old, and (2) age-related increases in activity, which may signal functional compensation.

Key words: positron emission tomography; cerebral blood flow; aging; memory; encoding; retrieval; recognition; recall; frontal lobes; functional reorganization; functional compensation
Compared to young adults, elderly adults perform poorly on a variety of memory tasks (for review, see Light, 1991; Craik and Jennings, 1992; Verhaeghen et al., 1993). In particular, old adults are impaired on episodic memory tests (Tulving, 1983), which involve retrieval of information about previously experienced events. These age-related memory deficits probably reflect anatomical and physiological deterioration of the aging brain (Kemper, 1984; Creasey and Rapoport, 1985; Coleman and Flood, 1987). New functional neuroimaging techniques, such as positron emission tomography (PET), now make it possible to study agerelated differences in neural activity in vivo while subjects are performing memory tasks.

Using PET, Grady et al. (1995) measured regional cerebral blood flow (rCBF) in young and old subjects while they were intentionally learning (encoding) and subsequently recognizing faces. During encoding, young subjects showed increased rCBF in the left prefrontal and right hippocampal regions, but old subjects did not show reliable activation in either of these two regions.

\footnotetext{
Received July 31, 1996; revised Oct. 2, 1996; accepted Oct. 3, 1996.

This work was supported by a post-doctoral fellowship of the International Human Frontier Science Program to R.C., grants from the National Alliance for Research on Schizophrenia and Depression and the Medical Research Council to S.K., and an endowment by Anne and Max Tanenbaum to E.T. We thank Douglas Hussey, Kevin Cheung, and Corey Jones for technical assistance.

Correspondence should be addressed to Roberto Cabeza, Rotman Research Institute of Baycrest Centre, 3560 Bathurst Street, North York, Ontario, Canada M6A 2 E1.

Copyright (C) 1996 Society for Neuroscience $0270-6474 / 96 / 170391-10 \$ 05.00 / 0$
}

During recognition, both young and old subjects showed increased blood flow in right prefrontal cortex, in keeping with similar observations concerning episodic retrieval in many previous PET studies (for review, see Tulving et al., 1994; Nyberg et al., 1996a; Cabeza and Nyberg, in press).

In another PET study of memory and aging, Schacter et al. (1996) scanned young and old subjects while they were recalling previously studied words. Both groups showed increased blood flow in hippocampal regions. In contrast, young adults but not older adults showed activation in anterior frontal regions. This result contrasts with the finding of Grady et al. (1995) of similar levels of frontal activation during recognition in young and old subjects. The differences in the outcomes of the two studies may be related to different measures of retrieval: recognition by Grady et al. (1995) and recall by Schacter et al. (1996). It is known that older people are particularly impaired on recall (Craik and McDowd, 1987), and it is widely believed that the integrity of frontal lobe structures is more critical for recall than for recognition (Moscovitch, 1992).

In this experiment, we used PET to compare $\mathrm{rCBF}$ in young and old volunteers while they studied word pairs, and during subsequent recognition and recall of the encoded information. The design of the experiment allowed us to examine age-related differences in activation during both encoding and retrieval (cf. Grady et al., 1995) and to compare retrieval in recall and in recognition (cf. Schacter et al., 1996). Furthermore, we were interested in identifying brain regions that show more activation 


\begin{tabular}{lcc}
\hline Table 1. Demographic and neuropsychological data & \\
& Young Ss & Older Ss \\
\hline Age & 25.7 & $70.5^{*}$ \\
Education (years) & 17.8 & 16.0 \\
Self-rated health (1 = bad, 5 = excellent) & 4.67 & 4.58 \\
Vocabulary (Mill Hill) & 22.3 & $28.3^{*}$ \\
Word fluency (FAS) & 50.5 & 48.2 \\
Recall (California Verbal Learning Test) & & \\
List A: trial 1 & 10.6 & 8.8 \\
List A: total trials 1-5 & 70.2 & $57.7^{*}$ \\
List B: recall & 10.2 & $7.1^{*}$ \\
List A: short-delay recall & 14.0 & $11.1^{*}$ \\
List A: short-delay cued recall & 15.0 & $11.8^{*}$ \\
\hline
\end{tabular}

${ }^{*} p<0.05$.

for old than young adults. Grady et al. (1994) found some of these regions in perceptual tasks in which old subjects performed as accurately as young subjects, whereas Grady et al. (1995) did not find them in a recognition memory task in which old subjects performed significantly worse than young adults. In the present study, we explored the issue in a group of high-functioning elderly who displayed a good level of memory performance.

\section{MATERIALS AND METHODS}

Subjects. The subjects were 12 young adults ( 6 male, 6 female; age range 19-31 years, mean age 26 years) and 12 old adults ( 5 male, 7 female; age range $67-75$ years, mean age 70 years). All subjects were right-handed and had no history of neurological or psychiatric illness. None of the subjects was taking medication or had a condition that could affect cerebral blood flow (e.g., high blood pressure), with the exception of one old subject who suffered from mild hypothyroidism. Young subjects were mainly undergraduate and graduate students of the University of Toronto, and old subjects were high-functioning community-dwelling individuals. All old subjects were college-educated, and half were selected from among the highest scorers in an elderly volunteer subject pool at the University of Toronto. As Table 1 indicates, the two groups were matched in education, self-rated health, and word fluency but differed in vocabulary (higher in old subjects) and recall on the California Verbal Learning Test (CVLT; higher in young subjects). The study was approved by the Human Subject Use Committee of the University of Toronto and the Baycrest Centre.

Procedure. Subjects were seen in the PET laboratory twice. During the first visit, they completed a health questionnaire, performed the required neuropsychological tests (Mill Hill, CVLT, and FAS), and practiced the tasks to be performed during the experiment (with different words than those used during the experiment proper). During the second session, anywhere from 3 to $7 \mathrm{~d}$ later, they underwent eight PET scans, one every 11 min. On each scan, the subjects saw a succession of 24 word pairs on a computer screen, presented at the rate of $5 \mathrm{sec} /$ pair $(4 \mathrm{sec}$ on the screen, $1 \mathrm{sec}$ interval). Subjects always responded to every pair by speaking a single word. Different sets of 24 word pairs were used in each scan. The sets were assigned to the eight scans in a randomly determined order for half of the subjects, and in the opposite order for the other half.

The eight scans corresponded to four cognitive tasks, each repeated once. The first and last scans were always baseline Reading tasks: subjects read each pair of words silently and spoke aloud the second member of the pair. The other three tasks-Encoding, Recognition, and Recall—are summarily described in Table 2 in terms of the visual display, instructions describing cognitive activity, and the required verbal response. The results of comparisons between the baseline Reading task and the three other tasks for the group of young subjects have been reported elsewhere (Cabeza et al., in press; Kapur et al., in press). The purpose of this report is to present the data on encoding, recognition, and recall for the old subjects and to compare these with those of the young group. The ordering of the tasks under scrutiny here was (1) recognition-encodingrecall-recall-encoding-recognition for half of the subjects, and (2) recall-encoding-recognition-recognition-encoding-recall for the other half. The mirror-image pattern controlled for linear order effects.

During the intervals before recall and recognition scans, subjects studied the pairs to be tested during the scan under the same instructions as in the encoding task. To attenuate differences in task difficulty between recognition and recall, the study list was presented once for recognition and twice for recall, faster for recognition ( 1 pair every $4 \mathrm{sec}$ ) than for recall (every $5 \mathrm{sec}$ ), and more separated from the test for recognition (5 min interval) than for recall $(2 \mathrm{~min})$. These differences in procedure were selected on the basis of the results of pilot studies. Reducing difficulty differences does not eliminate the main qualitative differences between recall and recognition tasks (e.g., recall involves generation while recognition does not), but it may alter some of the processing differences that exist between these tests in conditions in which recall is more demanding than recognition. After the eight scans, subjects were given "delayed" recognition and cued-recall tests for all of the words presented during the reading and encoding scans. The significance level for the analyses of behavioral data were set at 0.05 .

The presentation of each set of pairs started 35-45 sec before the beginning of the $60 \mathrm{sec}$ PET scan and finished 15-25 sec after the end of the scan. In the recall test, subjects were presented with the first word of each of the 24 studied pairs together with an invariant second word, as shown in Table 2, and they responded either with the correct word from the study list or with "pass." In the recognition test, the 18 word pairs in the middle of the sequence, coincident with the actual scan, were all "old," having been seen in the study list. The second word in the three studied pairs at the beginning of the list (before the start of the scan) and in three pairs near the end of the list (after the end of the scan) was replaced by a lure word. Thus, in both recall and recognition, all items during the $60 \mathrm{sec}$ scan window were potentially capable of prompting successful retrieval.

PET methods. PET scans were obtained with a GEMS-Scanditronix PC2048-15B head scanner using a bolus injection of $40 \mathrm{mCi}(1.48 \mathrm{GBq})$ of ${ }^{15} \mathrm{O}-\mathrm{H}_{2} \mathrm{O}$. The analyses of PET data involved four steps.

First, using Statistical Parametric Mapping (SPM95) software (Wellcome Department of Cognitive Neurology, London, UK) implemented in Matlab (Mathworks Inc., Sherborn, MA), the different images from each subject were (1) realigned to the first image, using a rigid body transformation, (2) transformed into a standard space (Talairach and Tournoux, 1988), and (3) smoothed using an isotropic Gaussian kernel of $15 \mathrm{~mm}$ FWHM (Friston et al., 1991, 1995).

Second, the value for each pixel in the images of each subject was divided by the average global CBF for the subject in the task (Fox et al., 1988) and reduced by the average value for the pixel across all tasks (Moeller and Strother, 1991). The latter adjustment reduces intergroup errors of registration and other global group differences. The resulting corrected values, therefore, show a proportional CBF change above and below zero, with zero representing the average value for the pixel across all tasks.

Third, a partial-least-squares analysis (PLS) (McIntosh et al., 1996) was performed on the data from the encoding, recognition, and recall tasks (the two scans in each task were averaged together). PLS is a multivariate method that has been adapted recently to analyze neuroimaging data. It uses all of the information contained within the images, and all of the information about the experimental design, in a single analytic step,

\section{Table 2. Conditions}

\begin{tabular}{|c|c|c|c|}
\hline Task & Visual input & Verbal output & Condensed instructions \\
\hline Encoding & parents-piano & piano & $\begin{array}{l}\text { Read the first word silently and the second word aloud, and try to remember } \\
\text { the pair by noting meaningful relations between the two words. }\end{array}$ \\
\hline Recognition & parents-piano & piano or pass & If you think the second word is the original one, read it aloud; otherwise, say pass \\
\hline Recall & parents-word? & piano or pass & If you can remember the original second word, say it aloud; otherwise say pass \\
\hline
\end{tabular}


making it more sensitive for detecting changes in activity than conventional univariate image subtraction methods. In most cases, the results from PLS and univariate subtractions will identify similar areas, but PLS will identify additional areas because of the increased sensitivity. For the present dataset, PLS was used to address the following question: "Is there a pattern of task-related image-wide activity that distinguishes young and old subjects?" PLS is designed to describe the relation between some exogenous source, such as experimental design or behavioral measures, and the functional brain images. In the case of the experimental design, it does so by first computing the cross-covariance between a matrix containing contrast vectors that code the experimental design and all of the voxels in each image for all subjects in all tasks. The cross-covariance matrix is then decomposed using singular value decomposition yielding pairs of latent variables. The first element of the pair represents a linear combination of contrasts that has the largest relation to (is most covariant with) the brain images, and the other element of the pair is a weighted linear combination of voxels that is most closely related to that combination of contrasts. (Because this image is derived from a singular value decomposition, it is called a singular image, and the values for these voxels are called saliences.) Stated somewhat differently, the first pair extracted represents the largest experimental effect and identifies both the contrast, or the combination of contrasts, representing the effect and the collection of voxels showing the effect. The brain image extracted can be interpreted, therefore, as depicting the nodes of a distributed system that is most affected by the manipulation. Successive extraction of latent variables will account for progressively less of the cross-covariance of the contrasts and images until all covariance is accounted for. Subject scores on the latent variables are derived by multiplying each individual image within a task by the voxel weights for a spatial pattern and summing across the cross-products. This gives a single score for each subject in each scan condition. Distribution of scores with respect to scan conditions was tested for significance using multiple linear regression of the scores on scan contrasts with the probabilities assigned using permutation tests. PLS contrasts included only task and group $\times$ task interactions; the group main effect is degenerate (zero), because it was partialed out through the mean adjustment.

Fourth, to clarify possible task $\times$ age interactions, $3 \times 2$ ANOVAs (encoding, recognition, recall tasks $\times$ young, old subjects) were performed on the corrected and adjusted $\mathrm{rCBF}$ values for the activated regions. Whereas the question addressed by PLS is asked at the level of the entire image, the ANOVAs were used to ask the question: "What is the relative contribution of a particular voxel to a singular image?" Similarly, PLS can be thought as providing an omnibus test of significance for task main effects and interactions, and the voxel-wise ANOVAs operate as a post hoc test to elucidate the interactions. Because the mean adjustment of rCBF controlled for the main effect of group, only the main effects of tasks and the tasks $\times$ group interaction are reported. Additionally, pairwise contrasts between the conditions differentiated by each latent variable were performed separately in each group.

\section{RESULTS}

\section{Behavioral data}

Behavioral results are shown in Table 3. Recognition was higher than recall, and differences between the two age groups did not reach statistical significance. On performance during the scans, a 2 (age: young vs old) $\times 2$ (test: recall vs recognition) ANOVA yielded a significant main effect of test $(F=11.7, p<0.003)$, a nonsignificant effect of age, and a nonsignificant test $\times$ age interaction. An ANOVA on performance after the scans also

\begin{tabular}{lll}
\hline Table 3. Behavioral data & & \\
& Young Ss & Older Ss \\
\hline Performance during the scans & & \\
$\quad$ Recognition (hits-false alarms) & 0.86 & 0.86 \\
$\quad$ Recall & 0.78 & 0.76 \\
Post-scans tests ${ }^{a}$ & & \\
$\quad$ Recognition (hits-false alarms) & 0.82 & 0.74 \\
$\quad$ Recall & 0.39 & 0.26 \\
${ }^{a}$ Tests of words presented during the encoding scans.
\end{tabular}

${ }^{a}$ Tests of words presented during the encoding scans. yielded a significant main effect of test $(F=106.4, p<0.0001)$, with no reliable effect of age or interaction. Although the age effect was not significant, it should be noted that the magnitude of the effect on performance after the scans is in line with many behavioral studies and might have been significant with a larger sample of subjects.

\section{PET data}

To simplify the description of PET results, we use the following terminology. Higher rCBF during encoding than during retrieval will be referred as encoding activation, and the opposite pattern as retrieval activation. Higher $\mathrm{rCBF}$ during recognition than during recall will be described as recognition activation, and the converse as recall activation. Lower $\mathrm{rCBF}$ in old than in young subjects will be referred to as age-related decrease, and higher $\mathrm{rCBF}$ in old than in young subjects will be described as age-related increase. Interactions between task and age are labeled accordingly. For example, higher $\mathrm{rCBF}$ in encoding than in retrieval but less so for old than young subjects is referred to as age-related decrease in encoding, and so forth.

The PLS analysis identified four patterns of rCBF changes across tasks (LV1 to LV4). These were all significant at $p<0.002$ according to the permutation tests and accounted for 50, 28, 14, and $8 \%$, respectively, of the cross-block covariance. LV1 and LV3 were similar in that they identified regions showing primarily encoding/retrieval differences in blood flow (see Fig. 1). They differed in that LV1 showed relevant regions as affected particularly by the young subjects, whereas LV3 depicted regions associated with marked encoding/retrieval $\times$ age interactions in $\mathrm{rCBF}$. LV2 and LV4 identified regions showing primarily blood flow differences between recognition and recall (see Fig. 2). LV2 differentiated between recognition and recall primarily in young subjects, and LV4 differentiated between recognition and recall primarily in old subjects.

The positive and negative saliences of LV1 and LV3 are listed in Table 4, and their rCBF changes are illustrated in Figure 3. The positive saliences of LV1 correspond to encoding activations (Fig. 3, 1-7). As indicated by the significant age $\times$ task interactions (see Table 4), encoding activations were generally stronger in young adults than in old adults. This idea is confirmed by pairwise contrasts between encoding and retrieval (average of recall and recognition) performed separately in each group (see the two rightmost columns of Table 4). In particular, encoding activations in left prefrontal, left precentral, left occipital, and right fusiform regions were significant in young but not in old subjects. In contrast, encoding activations in right Sylvian regions were significant in both groups. The negative saliences of LV1 correspond to retrieval activations (Fig. 3, 10-15), such as right frontal, parietal, temporal, and midbrain regions. Retrieval activations tended to be weaker in old adults. This was especially so for a medial right prefrontal cortex (Fig. 3, 10), where the old group did not show a significant difference between retrieval and encoding.

LV3 identified regions showing marked encoding/retrieval $\times$ age interactions in $\mathrm{rCBF}$. These regions can be classified into four groups. (1) There were regions showing encoding activations in the young but not in the old, such as the superior anterior cingulate (Fig. 3, 21) and the left temporal cortex (Fig. 3, 22). In these two regions, $\mathrm{rCBF}$ in old adults was higher during retrieval than during encoding. (2) There were regions showing retrieval activations in the young but not in the old, such as the inferior anterior cingulate (Fig. 3, 17) and the right medial frontal pole 

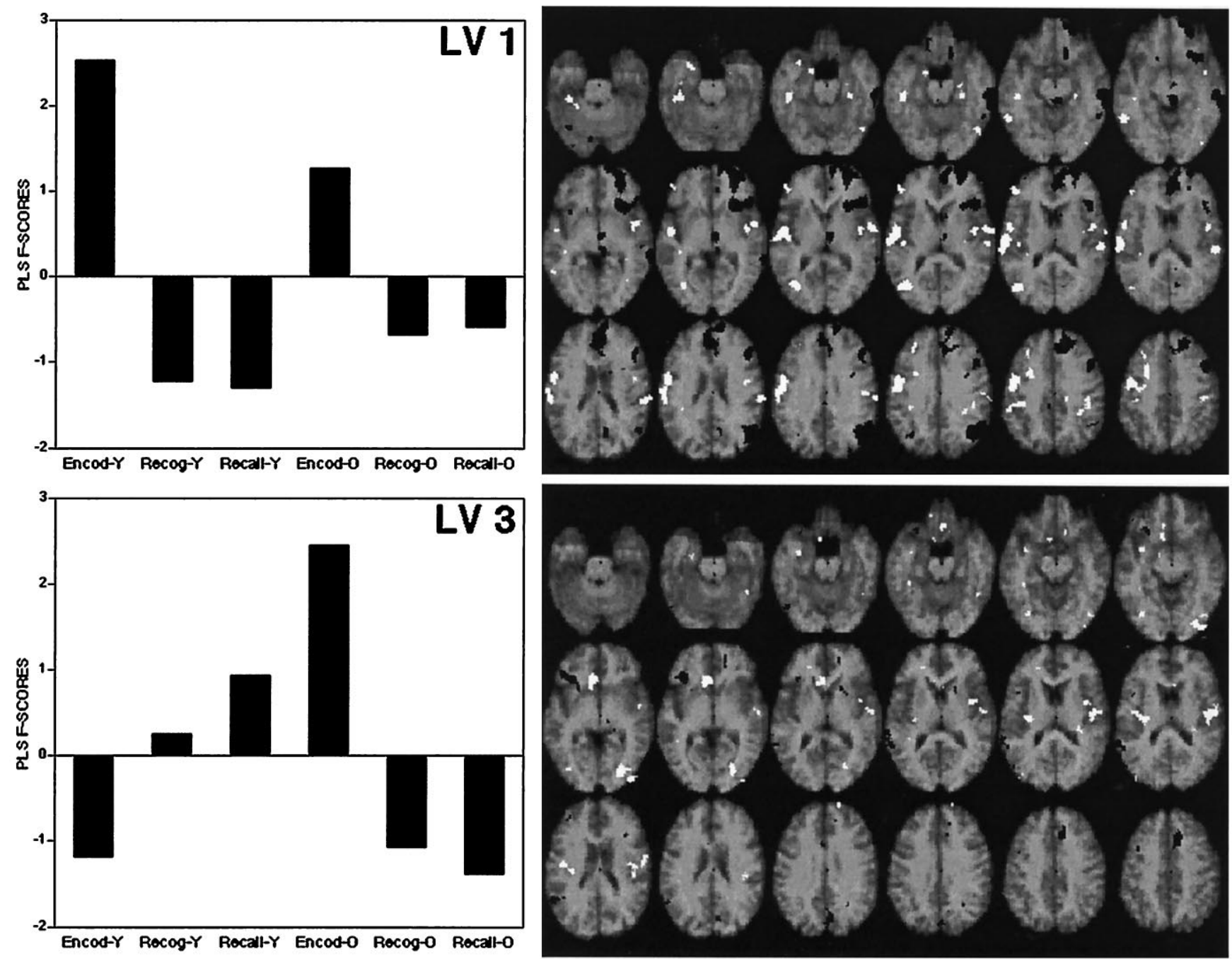

Figure 1. The graphs on the left correspond to scores for the first $(L V 1)$ and third $(L V 3)$ patterns of activation identified by the PLS analysis. On the right, the brain regions in which $\mathrm{rCBF}$ was positively (white) and negatively (black) associated to these patterns are shown overlaid on a standard MRI template of SPM 95. The horizontal slices are at intervals of $4 \mathrm{~mm}$, from $-28 \mathrm{~mm}$ below the AC-PC line (top left slice) to $40 \mathrm{~mm}$ above the AC-PC line (bottom right slice).

(the same region identified by LV1; Fig. 3, 10). In old subjects, the inferior anterior cingulate was more activated during encoding than during retrieval. (3) There were regions showing encoding activations in the old but not in the young, such as bilateral insular regions (Fig. 3, 18, 19) and the right occipital cortex (Fig. 3, 20). (4) There were regions showing retrieval activations in the old but not in the young, such the cuneus/precuneus region (Fig. 3, 23) and the left prefrontal cortex (Fig. 3, 24). The cuneus/precuneus region was particularly active during recognition, whereas the left prefrontal cortex was especially active during recall. In young subjects, the cuneus/precuneus region did not show a significant task effect, and the left prefrontal was more active during encoding than during retrieval.

The positive and negative saliences of LV2 and LV4 are listed in Table 5, and their rCBF changes are illustrated in Figure 4. LV2 identified regions that were differentially involved during recognition and recall, primarily in young subjects (see Fig. 4, 1-8). The positive saliences of LV2 are those regions showing recall activations (Fig. 4, 1-5), such as cerebellar and cingulate regions. The negative saliences of LV2 correspond to regions showing recognition activations (Fig. 4, 6-8), such as right temporal and parietal regions. In young adults, the regions associated with LV2 generally showed a "V" (positive saliences) or an "inverted-V" (negative saliences) pattern of $\mathrm{rCBF}$, in which encoding and recall are both differentiated from recognition. In old adults, this pattern was weak or nonexistent for most of these regions. As indicated by the pairwise contrasts in Table 5, the $\mathrm{rCBF}$ differences between recall and recognition identified by LV2 were pronounced in young adults and smaller or nonsignificant in old adults.

Finally, LV4 identified regions showing rCBF differences between recognition and recall in old subjects and no significant change in young subjects (see Fig. 4, 9-12). Regions in the right prefrontal cortex (Fig. 4, 9), right striatum (Fig. 4, 10) and left insula (Fig. 4, 12) were involved differently during recognition and recall by young and old subjects. A right anterior cingulate region (Fig. 4, 11)-more anterior than the left anterior cingulate differentiating recognition and recall in young subjects (Fig. 4, 2)-showed a recall activation in old subjects but not in young subjects. 

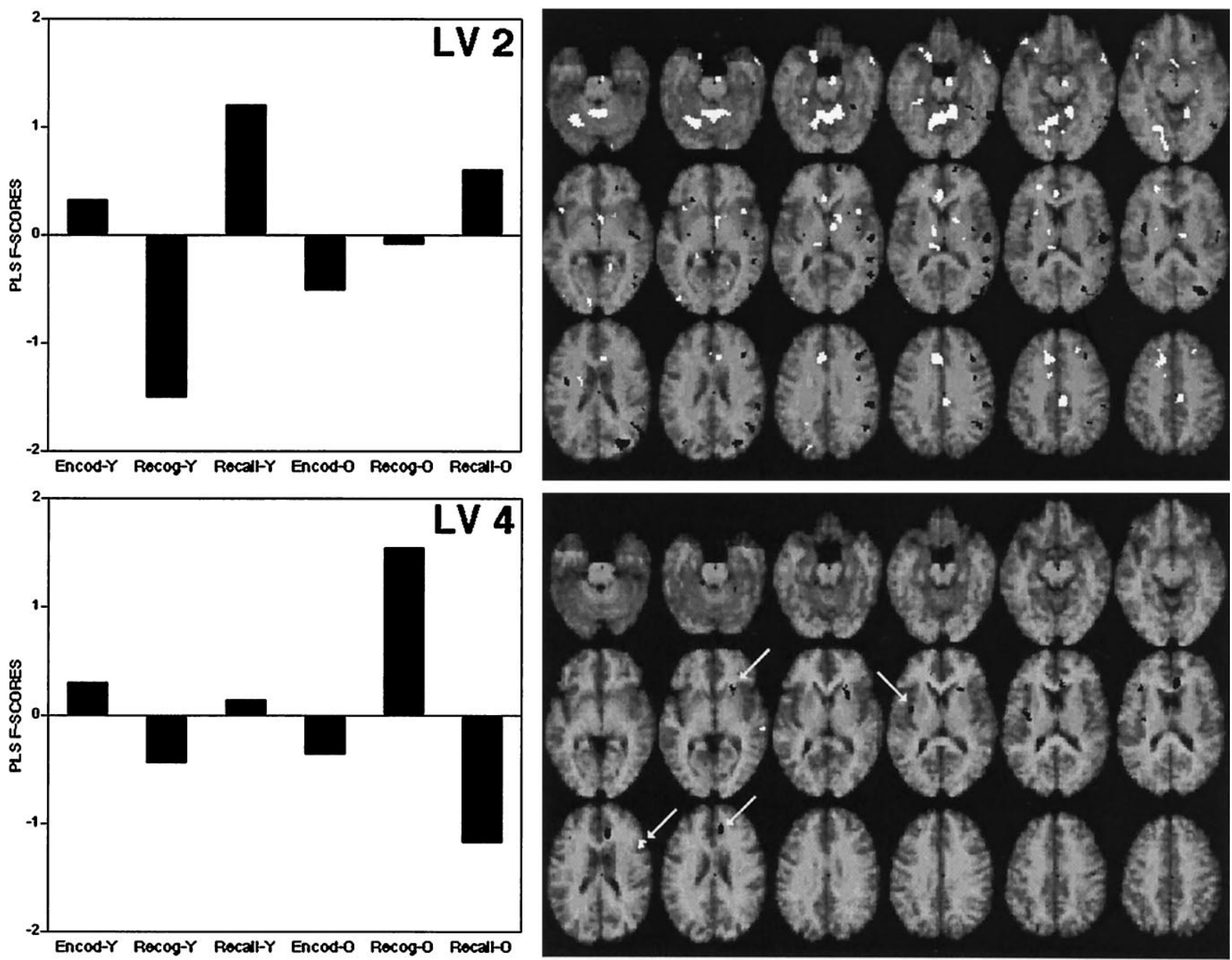

Figure 2. Scores and brain regions associated with $L V 2$ and $L V 4$. See legend to Figure 1.

\section{DISCUSSION}

The extensive data just presented are complex in detail but simple as a whole: old adults showed smaller differences in localized neuronal activity than young adults in some brain regions and larger differences in others. Age-related regional decreases in activation are usually interpreted as reflecting less efficient cognitive processing in old adults (Grady et al., 1994, 1995; Madden et al., 1996; Schacter et al., 1996). This interpretation may also apply to the present study, even if behavioral performance differences between the two groups were less striking in this study than in other comparable studies. First, PET can be more sensitive to cognitive dysfunction than behavioral tests and can detect, for example, brain metabolic reductions in Alzheimer's patients even when behavioral impairments are not yet apparent (Grady et al., 1988). Second, the effect of age-related decreases in activation in some brain regions may have been compensated for by agerelated increases in activation in other brain regions (Grady et al., 1994). Alternatively, rather than interpreting age-related decreases in activation in terms of processing deficiency and agerelated increases in activation in terms of functional compensation, different activation patterns in young and old subjects could be interpreted as indicating that the two groups performed the tasks differently, either by using a different strategy or by imple- menting the same strategy in different ways. Although we favor the first interpretation, we acknowledge that the second interpretation is also possible.

\section{Relation of aging to encoding activations}

Age-related decreases in encoding occurred primarily in left prefrontal and bilateral occipito-temporal regions. Consistent with the results of Grady et al. (1995), young adults differentially engaged the left prefrontal cortex during encoding but old adults did not. The involvement of the left prefrontal cortex during encoding has been observed repeatedly in PET studies (see, for example, Fletcher et al., 1995; Haxby et al., 1996) (for review, see Nyberg et al., 1996a; Cabeza and Nyberg, in press) and has been attributed to semantic processing (see, for example, Kapur et al., 1994). As for occipito-temporal regions, they are part of a ventral visual pathway involved in object perception (Ungerleider and Mishkin, 1982) and also seem to be involved in the encoding of new information in monkeys (Horel et al., 1987; Miller et al., 1991; Colombo and Gross, 1994) and humans (Haxby et al., 1996). Thus, age-related reductions in left prefrontal and left occipitotemporal regions suggest altered encoding processes in old adults.

Age-related increases in encoding occurred in bilateral insular regions. Although some age-related increases may reflect func- 

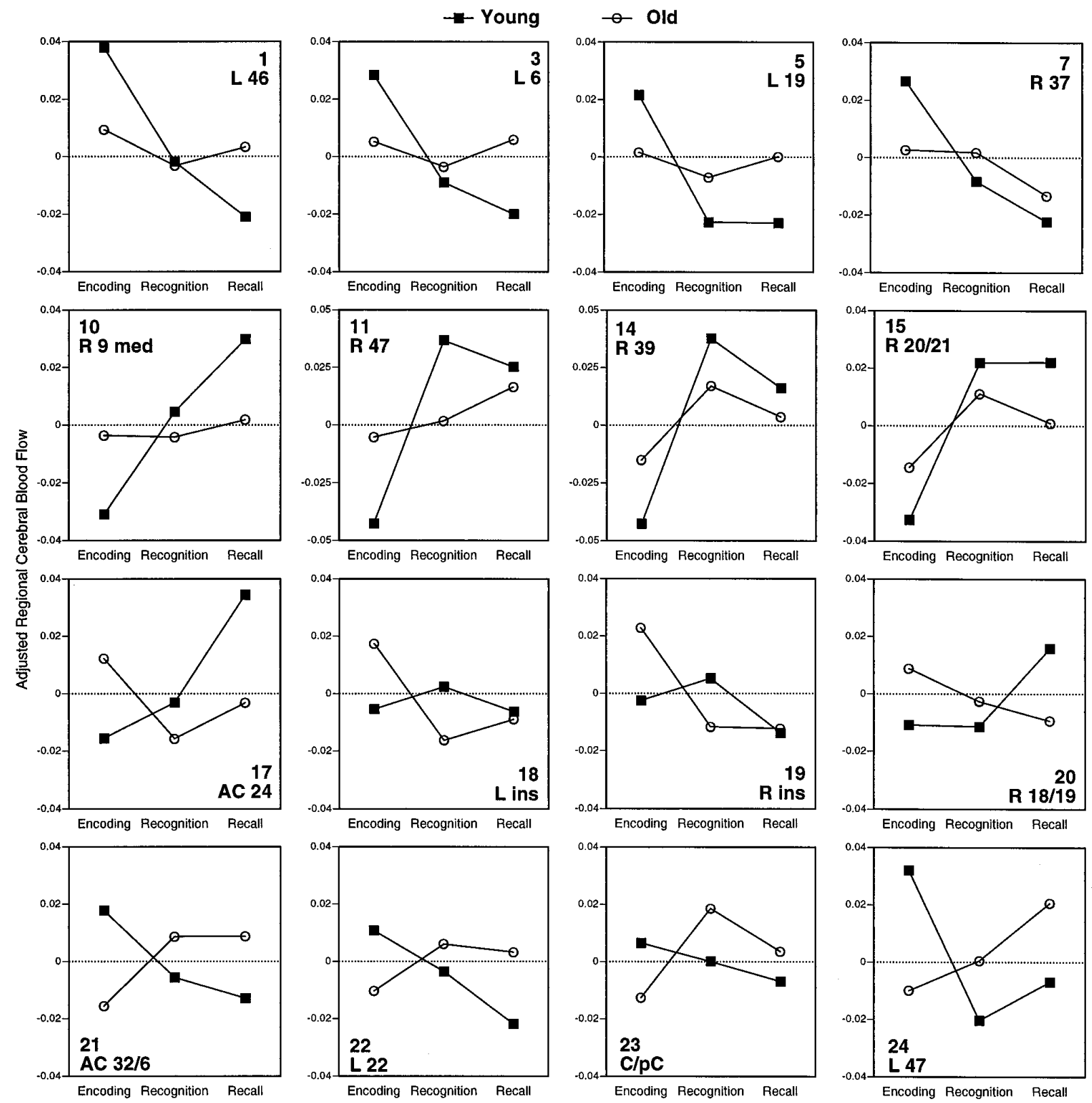

Figure 3. Changes in adjusted rCBF across tasks for young and old subjects in regions positively (1-7) and negatively (10-15) associated with LV1 and in regions positively (17-20) and negatively (21-24) associated with LV3. The top number in each graph corresponds to a saliency number in Table 4. Below this number, the hemisphere (Left or Right), a brain region (e.g., insula), and/or a Brodmann area are indicated.

tional compensation, it is possible that others signal use of less effective cognitive strategies. A possible method for deciding between positive or negative interpretations of age-related increases is to correlate rCBF in the region in question with cognitive performance. Because of small variability in memory performance, such correlations were generally nonsignificant in the present study. In the case of the right insula, however, there was a significant negative correlation $(r=-0.56, p<0.004$; see Fig. 5) between $\mathrm{rCBF}$ during the encoding scans and performance in the "delayed" recall test (for similar correlation analyses, see Cahill et al., 1996). This result suggests that the involvement of insular regions in old subjects, as well as in young subjects, may be disruptive rather than beneficial. A possible interpretation is that the recruitment of this region reflects a lack of inhibition. There is evidence that inhibitory processes influence task performance (Nyberg et al., 1996b) and that inhibition deficits play a role in cognitive aging (Hasher and Zacks, 1988).

\section{Relation of aging to retrieval activations}

Age-related decreases in retrieval occurred in several regions, including right prefrontal areas and right parietal regions. The age-related reduction in $\mathrm{rCBF}$ in the right prefrontal is consistent with the results of Schacter et al. (1996), and the reduction in the right parietal is consistent with the results of Grady et al. (1995). Activations in these two regions are commonly found in PET studies of episodic memory retrieval (for review, see Cabeza and Nyberg, in press). The right prefrontal cortex is assumed to play a role in supporting or guiding retrieval (Kapur et al., 1995; Nyberg 
Table 4. LV1 and LV3

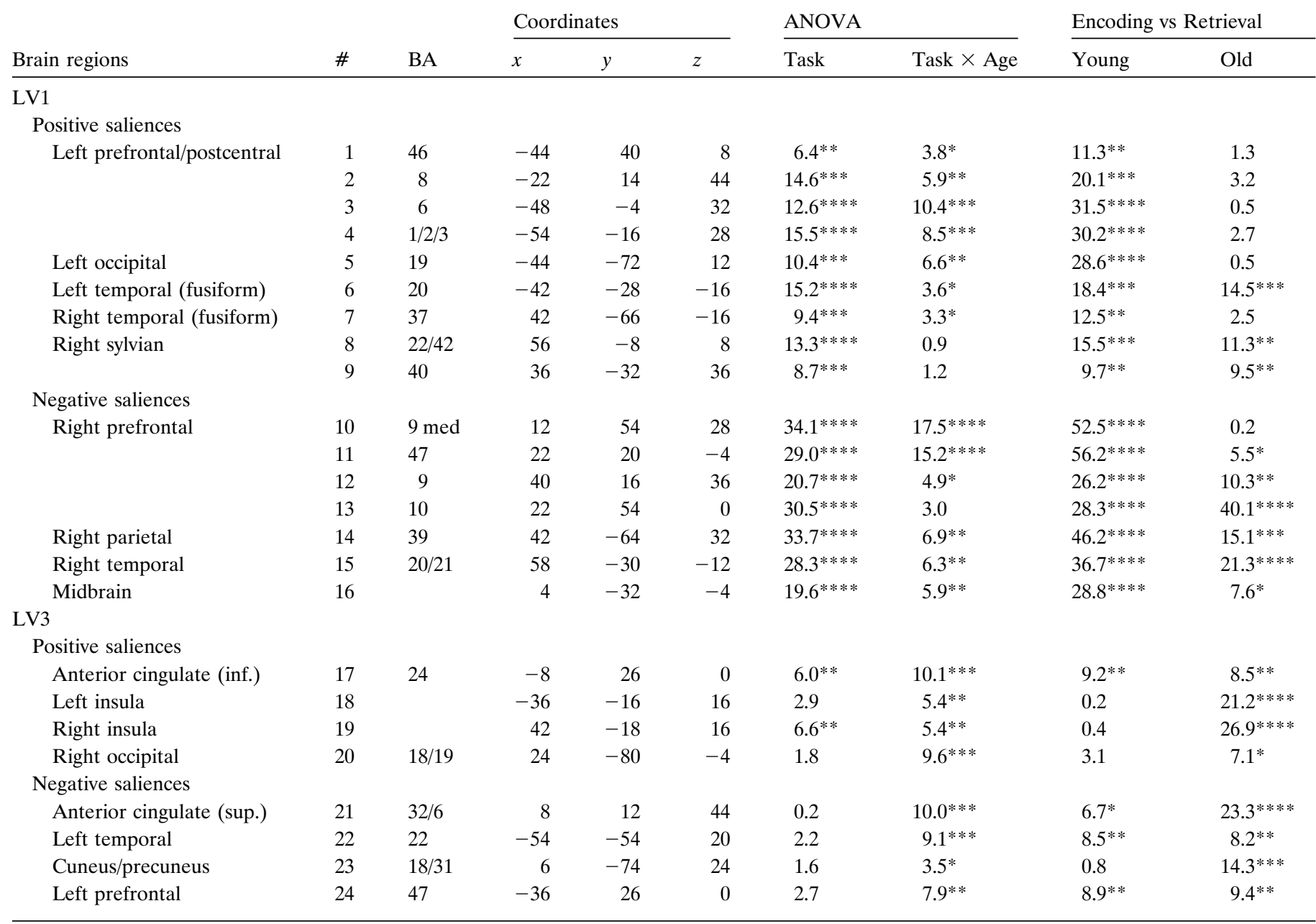

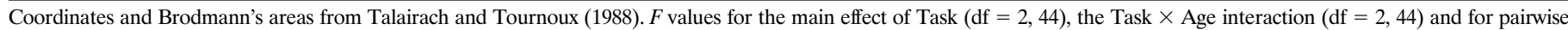
contrasts between encoding and retrieval (average of recognition and recall) in the young and old groups $(\mathrm{df}=1,22)$. ${ }^{*} p<0.05 ;{ }^{* *} p<0.01 ;{ }^{* * *} p<0.001 ;{ }^{* * *} p<0.0001$.

et al., 1995; Schacter et al., 1996), and the parietal cortex is assumed to be involved in the access to distributed "storage" systems (Andreasen et al., 1995). Accordingly, age-related reductions in right prefrontal and right parietal regions suggest altered retrieval operations in older adults. It should be noted, however, that in terms of the number of regions for which age $\times$ task interactions were seen, age-related reductions in retrieval were not as pronounced as age-related reductions in encoding. This pattern is consistent with the results of Grady et al. (1995) and with the conclusions drawn from cognitive studies comparing encoding and retrieval deficits in older adults (see, for example, Craik and Simon, 1980).

Age-related increases in retrieval occurred in two regions: the cuneus/precuneus region during recognition and the left prefrontal cortex during recall. PET evidence suggests that cuneus/precuneus plays a role in memory retrieval (Andreasen et al., 1995; Buckner et al., 1995; Fletcher et al., 1995; Kapur et al., 1995; Petrides et al., 1995). It is conceivable, therefore, that old adults' memory performance benefited from the recruitment of this region. The left prefrontal cortex is usually engaged in semantic memory retrieval tasks (Tulving et al., 1994; Nyberg et al., 1996a), such as generating words from semantic memory (see, for example, Petersen et al., 1989). Because cued-recall involves a semantic memory component (the generation of candidate responses) and an episodic memory component (the selection the target), old adults may have compensated for deficits in the episodic memory component (e.g., in the right prefrontal cortex) through the superior semantic memory component (e.g., in left prefrontal cortex).

More generally, frontal activity in young adults was leftlateralized during encoding and right-lateralized during recall, whereas old adults showed little frontal activity during encoding and a more bilateral pattern of frontal activation during retrieval. The lateralized pattern shown by young subjects is typically observed in PET studies of episodic memory, and it has been described in terms of a hemispheric encoding/retrieval asymmetry (HERA) model (Tulving et al., 1994; Nyberg et al., 1996a). The present results indicate that the typical asymmetrical encoding/ retrieval pattern does not hold in old age. In a PET study, it was found that unilateral localization of cognitive tasks in the left frontal lobe is shifted to the right hemisphere when the left is damaged (Buckner et al., 1996). It has also been reported that bilateral activation-with involvement of regions homologous to the ones responsible for normal function-may facilitate recovery after brain injury (Engelien et al., 1995). Although an interpretation in terms of functional compensation is consistent with the fact that old subjects performed at the same level as young subjects 

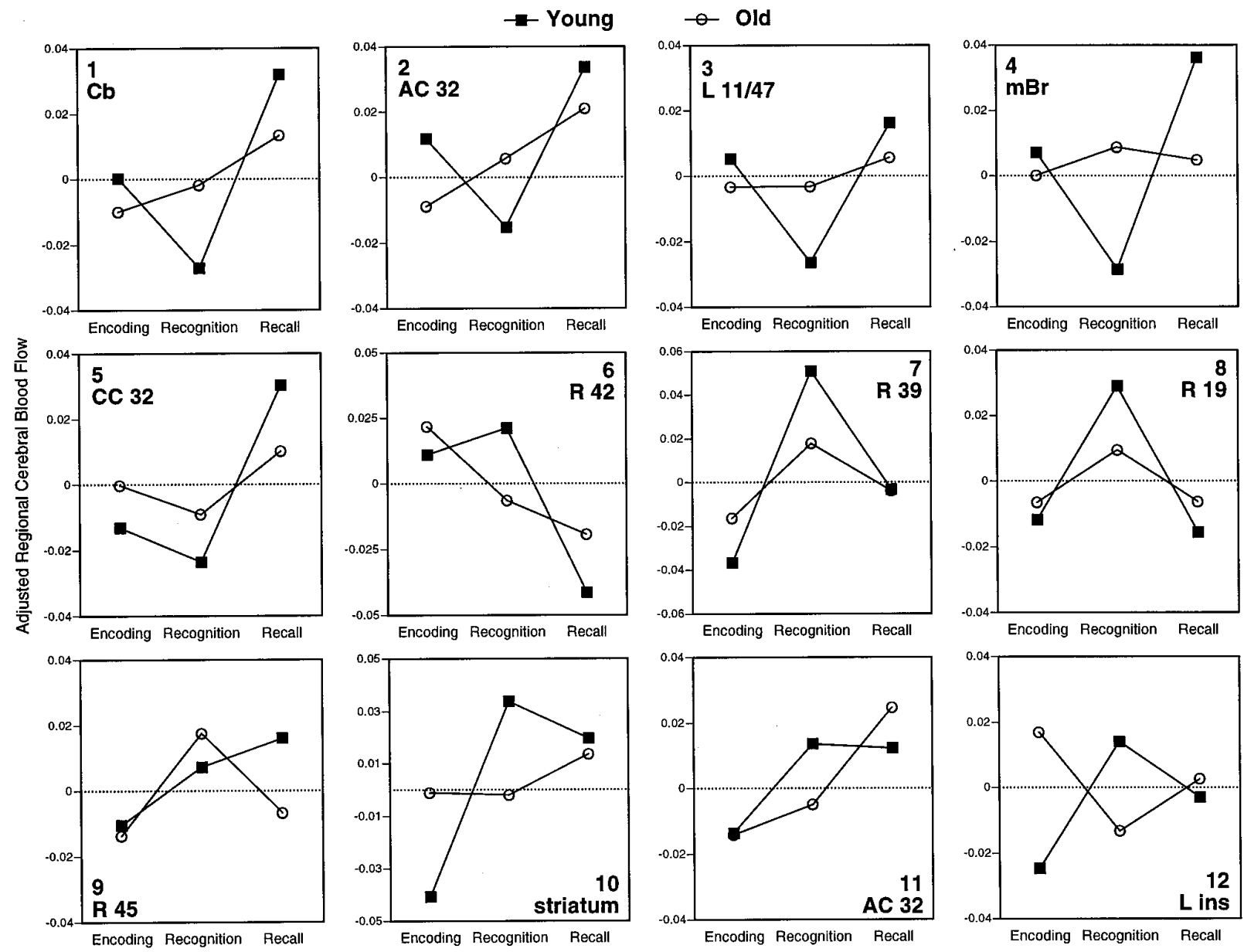

Figure 4. Changes in adjusted rCBF across tasks for young and old subjects in regions positively (1-5) and negative (6-8) associated with LV2 and in

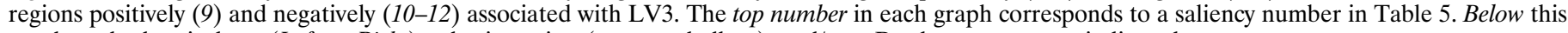
number, the hemisphere (Left or Right), a brain region (e.g., cerebellum), and/or a Brodmann area are indicated.

during the scans despite age-related decreases during both encoding and retrieval, the data reported here do not allow us to determine whether bilateral frontal activity in old subjects, as well as age-related increase in the cuneus/precuneus region, was beneficial or detrimental to memory performance.

\section{Relation of aging to recognition and recall activations}

LV2 identified recall activations primarily in cerebellar and cingulate regions and recognition activations mainly in right parietal and temporal regions. Age-related decreases occurred in both recognition and recall. We have no ready explanation for the age-related decreases in recognition. Recall activations may be related to the demand to generate an appropriate response in recall but not in recognition (for a more detailed discussion, see Cabeza et al., in press). Consistent with this idea, these regions were also engaged during encoding (see Fig. 4, 1-4), which involved a generation component as well. On this view, the present results might indicate that old subjects have difficulties with the generative process in recall, an idea that is in line with some theories of cognitive aging (e.g., Craik, 1983). However, the fact that old adults showed weaker recognition/recall differences in LV2 cannot be separated from the fact that they showed recognition/recall differences in other brain regions in LV4 (see Fig. 4, 9-12). Thus, rather than interpreting the results of LV2 in terms of deficient (or less flexible) processing in old adults, the combined results of LV2 and LV4 suggest that young and old adults performed recognition and recall tasks in a different way and, therefore, showed differential involvement of distinct brain regions. Because we attenuated performance differences between recall and recognition, it is a problem for future research to investigate age-related $\mathrm{rCBF}$ differences in conditions in which recall is much more demanding than recognition.

\section{CONCLUSIONS}

Old adults showed smaller differences in neuronal activity than young adults in some brain regions and larger differences in other in other regions. Age-related reductions occurred primarily in left prefrontal and temporo-occipital regions during encoding and right prefrontal regions during retrieval. These reductions suggest altered memory networks during both encoding and retrieval, but particularly during encoding where age-related reductions were more pronounced. Age-related increases may reflect the use of inadequate strategies in old adults (e.g., in insular regions during encoding), or they may signal beneficial compensatory activity (e.g., in the cuneus/precuneus region during recognition and the left prefrontal cortex during recall). Further work is necessary to evaluate these interpretations and to determine exactly how activity in these recruited areas is related to behavior. 
Table 5. LV2 and LV4

\begin{tabular}{|c|c|c|c|c|c|c|c|c|c|}
\hline \multirow[b]{2}{*}{ Brain regions } & \multirow[b]{2}{*}{$\#$} & \multirow[b]{2}{*}{$\mathrm{BA}$} & \multicolumn{3}{|c|}{ Coordinates } & \multicolumn{2}{|l|}{ ANOVA } & \multicolumn{2}{|c|}{ Recall vs Recognition } \\
\hline & & & $x$ & $y$ & $z$ & Condition & Age $\times$ Condition & Young & Old \\
\hline \multicolumn{10}{|l|}{ LV2 } \\
\hline Cerebellum & 1 & & 12 & -50 & -12 & $16.0^{* * * *}$ & $5.8^{* *}$ & $25.1^{* * * *}$ & $5.0^{*}$ \\
\hline Anterior cingulate & 2 & 32 & -8 & 22 & 32 & $8.0^{* *}$ & $3.4^{*}$ & $10.7^{* *}$ & 3.5 \\
\hline Left orbitofrontal & 3 & $11 / 47$ & -18 & 14 & -20 & $7.8^{* *}$ & $4.2^{*}$ & $14.5^{* * *}$ & 1.7 \\
\hline \multicolumn{10}{|l|}{ Negative saliences } \\
\hline Right temporal & 6 & 42 & 48 & -18 & 8 & $22.5 * * * *$ & $6.2 * *$ & $27.2 * * * *$ & 2.2 \\
\hline Right parietal & 7 & 39 & 42 & -58 & 28 & $26.0 * * * *$ & $5.0^{*}$ & $12.4^{* *}$ & $8.7^{* *}$ \\
\hline Right occipital & 8 & 19 & 30 & -76 & 20 & $10.7^{* *}$ & 2.3 & $10.8^{* *}$ & $8.2^{* *}$ \\
\hline \multicolumn{10}{|l|}{ LV4 } \\
\hline \multicolumn{10}{|l|}{ Positive saliences } \\
\hline Anterior cingulate & 11 & 32 & 6 & 36 & 24 & $11.6^{* * * *}$ & 2.7 & 0.01 & $14.9^{* * *}$ \\
\hline Left insula & 12 & & -28 & -18 & 12 & 0.2 & $13.2^{* * * *}$ & 2.2 & $5.0^{*}$ \\
\hline
\end{tabular}

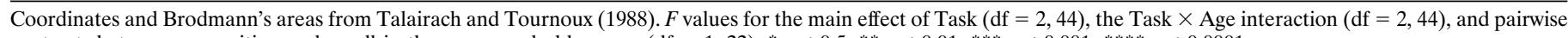
contrasts between recognition and recall in the young and old groups $(\mathrm{df}=1,22)$. ${ }^{*} p<0.5 ;{ }^{*} p<0.01 ;{ }^{* *} p<0.001 ;{ }^{* * * *} p<0.0001$.

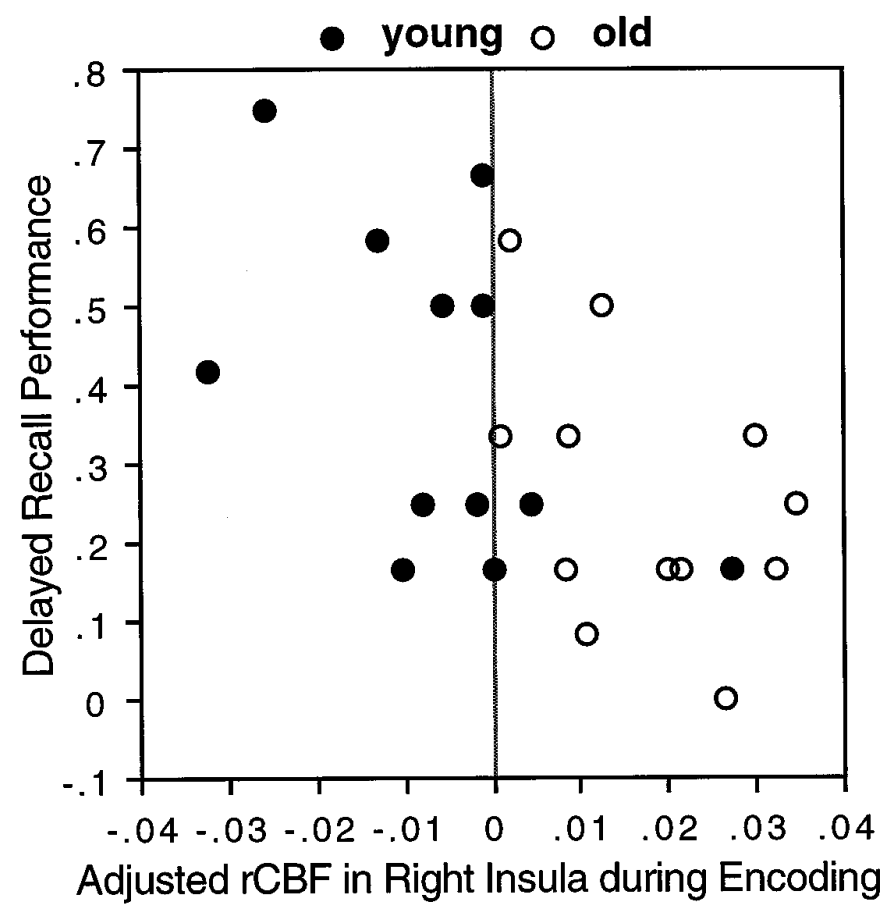

Figure 5. Significant negative correlation $(r=-0.56, p<0.004)$ between adjusted $\mathrm{rCBF}$ in the right insula $(x y z=42,-18,16)$ during the encoding scans and behavioral performance in the delayed recall test.

\section{REFERENCES}

Andreasen NC, O'Leary DS, Arndt S, Cizadlo T, Hurtig R, Rezai K, Watkins GL, Ponto LLB, Hichwa RD (1995) Short-term and longterm verbal memory: a positron emission tomography study. Proc Natl Acad Sci USA 92:5111-5115.

Buckner RL, Petersen SE, Ojemann JG, Miezin FM, Squire LR, Raichle ME (1995) Functional anatomical studies of explicit and implicit memory retrieval tasks. J Neurosci 15:12-29.
Buckner RL, Corbetta M, Schatz J, Raichle ME, Petersen SE (1996) Preserved speech abilities and compensation following prefrontal damage. Proc Natl Acad Sci USA 93:1249-1253.

Cabeza R, Nyberg L (1996) Imaging cognition: an empirical review of PET studies with normal subjects. J Cognit Neurosci, in press.

Cabeza R, Kapur S, Craik FIM, McIntosh AR, Houle S, Tulving E (1996) Functional neuroanatomy of recall and recognition: a PET study of episodic memory. J Cognit Neurosci, in press.

Cahill L, Haier RJ, Fallon J, Alkire M, Tang C, Keator D, Wu J, McGaug JL (1996) Amygdala activity at encoding correlated with long-term free recall of emotional information. Proc Natl Acad Sci USA, in press.

Coleman PD, Flood DG (1987) Neuron numbers and dendritic extent in normal aging and Alzheimer's disease. Neurobiol Aging 8:521-545.

Colombo M, Gross CG (1994) Responses of inferior temporal cortex and hippocampal neurons during delayed matching to sample in monkeys (Macaca fascicularis). Behav Neurosci 108:443-455.

Craik FIM (1983) On the transfer of information from temporary to permanent memory. Philos Trans R Soc Lond [Biol] 302:341-359.

Craik FIM, Jennings JM (1992) Human memory. In: Handbook of aging and cognition (Craik FIM, Salthouse TA, eds), pp 51-109. Hillsdale, NJ: Erlbaum.

Craik FIM, McDowd JM (1987) Age differences in recall and recognition. J Exp Psychol 13:474-479.

Craik FIM, Simon E (1980) Age differences in memory: the roles of attention and depth of processing. In: New directions in memory and aging (Poon LW, Fozard JL, Cermak LS, Arenberg D, Thompson LW, eds), pp 95-112. Hillsdale, NJ: Erlbaum.

Creasey H, Rapoport SI (1985) The aging human brain. Ann Neurol 17:2-10.

Devinsky O, Morrell MJ, Vogt BA (1995) Contributions of anterior cingulate cortex to behaviour. Brain 118:279-306.

Engelien A, Silbersweig D, Stern E, Huber W, Doring W, Frith C, Frackowiak RS (1995) The functional anatomy of recovery from auditory agnosia: a PET study of sound categorization in a neurological patient and normal controls. Brain 118:1395-1409.

Fletcher PC, Frith CD, Grasby PM, Shallice T, Frackowiak RSJ, Dolan RJ (1995) Brain systems for encoding and retrieval of auditory-verbal memory: an in vivo study in humans. Brain 118:401-416.

Fox PT, Mintun MA, Reiman EM, Raichle ME (1988) Enhanced detection of focal brain responses using intersubject averaging and change distribution analysis of subtracted PET images. J Cereb Blood Flow Metab 8:642-653. 
Friston KJ, Frith CD, Liddle PF, Frackowiak RSJ (1991) Comparing functional (PET) images: the assessment of significant change. J Cereb Blood Flow Metab 11:690-699.

Friston KJ, Holmes AP, Worsley KJ, Poline J-P, Frith CD, Frackowiak RSJ (1995) Statistical parametric maps in functional imaging: a general linear approach. Hum Brain Mapp 2:189-210.

Grady CL, Haxby JV, Horwitz B, Sundaram M, Berg G, Schapiro MB, Friedland RP, Rapoport SI (1988) A longitudinal study of the early neuropsychological and cerebral metabolic changes in dementia of the Alzheimer type. J Clin Exp Neuropsychol 10:576-596.

Grady CL, Maisog JM, Horwitz B, Ungerleider LG, Mentis MJ, Salerno JA, Pietrini P, Wagner E, Haxby JV (1994) Age-related changes in cortical blood flow activation during visual processing of faces and location. J Neurosci 14:1450-1462.

Grady CL, McIntosh AR, Horwitz B, Maisog JM, Ungerleider LG, Mentis MJ, Pietrini P, Schapiro MB, Haxby JV (1995) Age-related reductions in human recognition memory due to impaired memory encoding. Science 269:218-221.

Hasher L, Zacks RT (1988) Working memory, comprehension and aging: a review and a new view. Psychol Learn Motiv 22:193-225.

Haxby JV, Ungerleider LG, Horwitz B, Maisog JM, Rapoport SL, Grady CL (1996) Face encoding and recognition in the human brain. Proc Natl Acad Sci USA 93:922-927.

Horel JA, Pytko-Joiner DE, Voytko ML, Salsbury K (1987) The performance of visual tasks while segments of the inferotemporal cortex are suppressed by cold. Behav Brain Res 23:29-42.

Kapur S, Rose R, Liddle PF, Zipursky RB, Brown GM, Stuss D, Houle S, Tulving E (1994) The role of left prefrontal cortex in verbal processing: semantic processing or willed action? NeuroReport 5:2193-2196.

Kapur S, Craik FIM, Jones C, Brown GM, Houle S, Tulving E (1995) Functional role of the prefrontal cortex in memory retrieval: a PET study. NeuroReport 6:1880-1884.

Kapur S, Tulving E, Cabeza R, McIntosh RA, Houle S, Craik FIM (1996) Neural correlates of intentional learning of verbal materials: a PET study in humans. Cognit Brain Res, in press.

Kemper T (1984) Neuroanatomical and neuropathological changes in normal aging and in dementia. In: Clinical neurology of aging (Albert M, ed), pp 9-52. New York: Oxford UP.

Light LL (1991) Memory and aging: four hypotheses in search of data. Annu Rev Psychol 42:333-376.

Madden DJ, Turkington TG, Coleman RE, Provenzale JM, DeGrado TR, Hoffman JM (1996) Adult age differences in regional cerebral blood flow during visual word identification: evidence from $\mathrm{H}_{2}{ }^{15} \mathrm{O}$ PET. Neuroimage 3:127-142.

McIntosh AR, Bookstein FL, Haxby JV, Grady CL (1996) Spatial pattern analysis of functional brain images using partial least squares. Neuroimage 3:143-157.
Miller EK, Li L, Desimone R (1991) A neural mechanism for working and recognition memory in inferior temporal cortex. Science 254:1377-1379.

Moeller JR, Strother SC (1991) A regional covariance approach to the analysis of functional patterns in positron emission tomographic data. $\mathrm{J}$ Cereb Blood Flow Metab 11:A121-A135.

Moscovitch M (1992) Memory and working-with-memory: a component process model based on modules and central systems. J Cognit Neurosci 4:257-267.

Nyberg L, Tulving E, Habib R, Nilsson L-G, Kapur S, Houle S, Cabeza R, McIntosh AR (1995) Functional brain maps of retrieval mode and recovery of episodic information. NeuroReport 7:249-252.

Nyberg L, Cabeza R, Tulving E (1996a) PET studies of encoding and retrieval: the HERA Model. Psychonom Bull Rev 3:134-147.

Nyberg L, McIntosh AR, Cabeza R, Nilsson L-G, Houle S, Habib R, Tulving E (1996b) Network analysis of positron emission tomography regional cerebral blood flow data: ensemble inhibition during episodic memory retrieval. J Neurosci 16:3753-3759.

Paus T, Petrides M, Evans AC, Meyer E (1993) Role of the human anterior cingulate cortex in control of oculomotor, manual, and speech responses: a positron emission tomography study. J Neurophysiol 70:453-469.

Petersen SE, Fox PT, Posner MI, Mintum M, Raichle ME (1989) Positron emission tomographic studies of the processing single words. J Cognit Neurosci 1:153-170.

Petrides M, Alivisatos B, Evans A (1995) Functional activation of the human ventrolateral frontal cortex during mnemonic retrieval of verbal information. Proc Natl Acad Sci USA 92:5803-5807.

Schacter DL, Alpert NM, Savage CR, Rauch SL, Albert MS (1996) Conscious recollection and the human hippocampal formation: evidence from positron emission tomography. Proc Natl Acad Sci USA 93:321-326.

Schacter DL, Savage CR, Alpert NM, Rauch SL, Albert MS (1996) The role of hippocampus and frontal cortex in age-related memory changes: a PET study. NeuroReport 7:1165-1169.

Talairach J, Tournoux P (1988) A co-planar stereotactic atlas of the human brain. Stuttgart: Thieme.

Tulving E (1983) Elements of episodic memory. London: Oxford UP.

Tulving E, Kapur S, Craik FIM, Moscovitch M, Houle S (1994) Hemispheric encoding/retrieval asymmetry in episodic memory: positron emission tomography findings. Proc Natl Acad Sci USA 91:2016-2020.

Ungerleider LG, Mischkin M (1982) Two cortical visual systems. In: Analysis of visual behavior (Ingle DJ, Goodale MA, Mansfield RJW, eds), pp 549-589. Cambridge, MA: MIT.

Verhaeghen P, Marcoen A, Goossens L (1993) Facts and fiction about memory aging: A quantitative integration of research findings. J Gerontol 48:157-171. 